\title{
Applied Anthropology and Business Diversity Management
}

\author{
Hector N. Qirko \\ College of Charleston
}

In the early 1990s, the concept of workforce diversity assumed prominence in business, particularly in the United States, and a large number of organizations instituted diversity management programs. Anthropological method and theory are consistent with the goals of diversity management, and the opportunity for applied anthropologists to contribute in this area seemed ideal. However, twenty years later, although diversity remains an important social issue and a relevant concern to businesses and their workforces, consumers, and communities, the applied anthropology presence in organizational diversity management appears to be minimal. This paper provides support for this claim and explores reasons, from both anthropological and business points of view, why this may be the case. It concludes by suggesting that applied anthropology can and should make more significant contributions to this field.

\section{INTRODUCTION}

In the early 1990s, many American businesses, governmental, educational, and other organizations began to develop and implement strategies for managing workforce diversity. Several factors influenced this trend, including globalization, the shift to a service economy, and organizational emphases on teams and knowledge workers (Ashakanasy, Härtel, \& Daus, 2002). However, it may have been most directly spurred by the Hudson Institute's widely read Workforce 2000: Work and Workers for the Twenty-First Century (Johnston \& Packer, 1987). This report predicted a changing U.S. labor force throughout the 1990s in which decreasing numbers of white males would be represented. By 2000, according to the Hudson Institute, 80 percent of new entrants to the labor force would be people of color, women, and immigrants. The report therefore underscored a need for businesses to effectively address workforce changes in order to successfully compete.

Many subsequent publications discussed the importance of organizational workforce diversity (e.g., Cox, 1993, Cox \& Blake 1991; Jamieson \& O'Mara, 1991; Loden \& Rosener, 1991; for an overview, see Fine, 1996). These typically addressed the "business case" for diversity on several fronts: first, the competitive advantage of attracting and retaining the best talent as drawn from an increasingly diverse pool and, second, the value of increased workforce diversity in itself, in terms of creative synergy, consequent organizational productivity, and in 
providing a fuller understanding of an increasingly diverse marketplace (Lattimer, 1998; Kochan et al., 2003; Konrad, 2003).

One of the most influential diversity management models in the business community was developed by R. Roosevelt Thomas, Jr., particularly in "From affirmative action to affirming diversity," which appeared in the Harvard Business Review (1990), and his book Beyond Race and Gender: Unleashing the Power of Your Total Workforce by Managing Diversity (1991). Thomas, like others, took workforce diversity beyond a social good to the bottom-line: The cover of his bestselling paperback warned that "By the year 2000 only one in every seven new employees will be the standard-issue white male. The ability to manage workforce diversity successfully has become a business imperative for the next decade- and a basic strategy for corporate survival."

Thomas" model rests on a broad conceptualization of diversity as the mix of similarities and differences in a given organization, potentially involving many dimensions, including race, ethnicity, gender, age, religion, educational level, geographic origin, sexual orientation, and others derived solely from the organizational context itself, such as job function, location, and tenure. As Cox puts it, diversity is "the representation, in one social system, of people with distinctly different group affiliations of cultural significance" $(1993$, p. 6), but these affiliations need not be associated with societal identity groups, and may be fluid and transitory in nature.

Thus to Thomas diversity is "beyond" race and gender, and so, in a sense, beyond racism and sexism as well. In this view, demographic representation is to be sought and maintained, especially as it relates to historically under-represented groups. However, successful management of diverse talents and mixes involves addressing the potential impact of any and all differences, even future or unobserved ones, on organizational culture (Thomas, 2010a). This is because organizational tensions related to diversity will often be complex and unexpected. For example, Thomas describes a case where African-American members of a workforce displayed significantly lower levels of organizational satisfaction than other groups. Although racism was concluded to be the cause by management,

"[B]lacks disproportionately worked in a function held in relatively low regard by the organization and also in a plant located in a geographic site considered to be an undesirable place to live. These functional and geographic considerations proved more significant in prompting blacks to report higher levels of dissatisfaction than other groups in the company than did racism. Any efforts to address the perceived racism - no matter how successful - would not have included the complexities associated with functions and geographic locations" (Thomas, 2010b, p. 50).

Therefore managing diversity complements, but is not identical to, affirmative action efforts. Affirmative action initiatives are a temporary means to increase the representation of women and minorities in areas from which they have historically been excluded (Wilcher, 2010). However, to Thomas these initiatives are insufficient in terms of business competitiveness, because other dimensions of difference may be as, or more, relevant to organizational success in particular settings. Further, while affirmative action policies facilitate employees" access to organizations and desirable positions within them, these policies do not address how a more diverse workforce resulting from such increased access affects organizational competitiveness and productivity. In addition, the perceived inequality of affirmative action policies, however necessary and justified 
they may be, often leads to a "reverse discrimination" backlash that can cause problems, particularly as anti-affirmative action sentiments are increasingly legitimized in the courts and society as a whole (Schwartz, 2000).

Organizations often invest in what are generally called "understanding differences" programs. These involve training and workshops (e.g., many varieties of diversity awareness training), as well as the celebration of particular identity groups through festivals, lecture series, etc., and which often coincides with federal observances (e.g., "National Hispanic Heritage Month"). Such initiatives can increase familiarity, tolerance, and respect among diverse groups in organizations. However, to Thomas these approaches fall too short of effective diversity management, in that only selected dimensions of difference are addressed, and the increased awareness and communication that such training and events may promote do not necessarily translate to increased organizational competitiveness (Thomas, 1992, p. 314). In fact, if these initiatives stand alone, they can raise sensitive issues without adequately addressing them, and, thus, have negative consequences (Kalev, Kelly, \& Dobbin, 2006; Kidder, Lankau, ChrobotMason, Mollica, \& Friedman, 2004).

Therefore, managing diversity, while involving both affirmative action and understanding difference components, is fundamentally "a comprehensive managerial process for developing an environment that works for all employees" (Thomas, 1991, p. 10). Managing diversity focuses primarily on the effectiveness of organizational culture, as reflected in formal and informal systems and practices, in addressing diversity to promote organizational goals. All facets of an organization - recruitment, hiring, promotions, training, etc. - must be assessed with respect to this linkage between diversity and organizational goals and reinforced or, if necessary, redesigned accordingly. Organizations must "build a house for diversity" rather than merely encourage access to and dialogue within existing structures (Thomas \& Woodruff, 1999).

Crucial to the diversity management process is the cultural audit or assessment which, as Thomas's consulting firm webpage describes, "examines and explains the common rules of behavior and underlying beliefs of an organization [and] identifies sources of diversity tension and leverage points that shape culture" (http://www.rthomasconsulting.com/). An audit identifies the mix of relevant diversity dimensions in particular organizations at a given time, as well as the effectiveness of systems and practices in managing both present and future diversity. Most importantly, it identifies the fundamental cultural (and subcultural) assumptions (as in Schein, 1992) that underlie organizational action. It is an instrument to explore diversity-related organizational culture, in other words, and how that culture relates to diversity management goals. As Jayne and Dipboye find in their review of research on effective diversity management, "A thorough needs assessment of the people, jobs, and organization ensures that issues related to diversity are framed accurately and that the right interventions are identified" (2004, p. 416).

However, Thomas does not elaborate methodologically - his instructions to businesses are simply to assess current organizational diversity issues in formal and informal systems and practices with an eye toward "cultural roots" (Thomas, 1991, p. 14). It is left to organizations to develop methods that will be effective in this pursuit. Diversity management literature in general follows Thomas in suggesting the importance of cultural audits as organizational "snapshots" without delineating specific methods, often simply suggesting the need to hire external consultants with the required expertise (e.g., Cox, 1993, pp. 237-238; Loden, 1996, pp. 130-131; Mor Barak, 2005, p. 215; although see Gardenswartz \& Rowe, 2010). 


\section{APPLIED ANTHROPOLOGY}

The potential relevance of applied anthropology to diversity management efforts, and in particular to cultural audits, is easy to see. Applied anthropology is the application of anthropological data, perspectives, theory, and methods to identify, assess, and solve problems it is anthropology "put to use" (van Willigen, 2002, p. 7). Although it can involve any of the four major anthropological subfields - archaeology, biological/physical anthropology, anthropological linguistics, and sociocultural anthropology - the latter's emphasis on cultural variation is most clearly relevant to diversity management. Applied cultural anthropologists often work in one or more of three broad roles: gathering and analyzing data about specific problems; evaluating the effectiveness of existing programs or policies; and predicting the likely effects of projected initiatives (Chambers, 1985; van Willigen 2002). The most important skill involved is knowledge about cultural properties and processes and about the methods through which to identify them in specific settings. Although anthropology has historically been associated with the study of non-Western societies, applied anthropologists often work in their own cultural contexts, questioning assumptions and "defamiliarizing" to critically assess culture even in the most familiar settings (Marcus \& Fischer, 1986; Podolefsky, 2008). A methodological fundamental is ethnography, the systematic description of a specific culture, involving immersion through observation, interviews, and other methods. While ethnographers have traditionally focused on qualitative research, a "judicious mixing" of qualitative and quantitative approaches (Pelto \& Pelto, 1978, p. ix) is increasingly common today. More important than specific methods used, however, is the premise that ethnographers primarily study culture "from the ground up" - that is, inductively, as experienced by participants in a given setting, rather than on the basis of theoretical dictates (Baba, 2000; Chambers, 1985; Nolan, 2008).

Anthropologists are therefore particularly qualified to assist in managing diversity efforts, given their understanding of the acquisition and transmission of culture, cultural variability and change, and subcultural and multicultural relationships (Jordan, 2010). And beginning roughly with the involvement of social scientists in the Western Electric Company Hawthorne studies in the 1930s, applied anthropologists have often worked with the organizational cultures of business, industry and occupations (Baba, 2005; Gwynne, 2003; Jordan, 2010; Schwartzman, 1992). In these contexts, anthropologists contribute by explaining "culturally grounded systems of practice and meaning that affect people's work behavior" and, not infrequently, in "diagnosing problems and recommending solutions that arise when employees from different cultures work together" (Baba, 2005, p. 250).

Thus diversity management appears an ideal area for anthropological involvement, and there has indeed been some anthropological attention paid to the subject (e.g., Caulkins \& Hyatt, 1999; Essed, 2002; Giovanni \& Rosansky, 1990; Kogod, 1994; Walck \& Jordan, 1995). However, the discipline's current applied contributions to diversity management, and particularly to cultural audits, do not appear to be plentiful. This is surprising, because in the twenty years since Thomas and others popularized the concept of diversity, it has become a buzzword in business in the United States and, increasingly, around the world. Most Fortune 500 companies presently have some form of diversity program in place, as do many other businesses (Bennett, 2010; Jayne \& Dipboye, 2004; Kalev et al., 2006; Ryan, Hawdon, \& Brannick, 2002; SHRM, 2008). 


\section{ANTHROPOLOGICAL INVOLVEMENT IN DIVERSITY MANAGEMENT}

While it is difficult to adequately assess current applied anthropological involvement in diversity management programs, several indicators support the likelihood that it is minimal. For example, very few recent papers presented at recent anthropology meetings directly discuss applied diversity management projects. The Society for Applied Anthropology is the largest applied anthropology organization in the United States, with roughly 2700 members (http://www.copaa.info/). An online keyword "diversity" search of its six most recent annual meeting programs for paper titles and abstracts describing diversity management projects in not only in business but agency, community, and educational organizations reveals rather startling numbers: for 2010 and 2011, only two; for 2008 and 2009, three; and four each for 2006 and 2007 -- this out of an approximate annual total of 680 papers (http://www.sfaa.net/). Another important applied anthropology organization is the National Association for the Practice of Anthropology, with over 1000 members. (http://practicinganthropology.org/). NAPA is a section of the American Anthropological Association, and its members present papers at annual AAA meetings. A similar "diversity" keyword search of the AAA annual programs available online finds only five papers given in 2009 and four in 2010 - in this case, out of over 550 and 800 multiple paper sessions respectively (http://www.aaanet.org/meetings/program/).

Another indication of the apparent lack of applied anthropological involvement in organizational diversity management programs is the scarcity of relevant publications in applied anthropology journals. A "diversity" keyword search was conducted of online publication indexes of Human Organization, the leading journal of applied anthropology in the United States, and Practicing Anthropology, a career-oriented journal primarily directed at anthropologists working outside of academia (both are published by the SFAA). Titles and abstracts were searched for content related in any way to organizational diversity published since 1991, when managing diversity theory was explicitly articulated by Thomas and others (and coincidentally, when PA began publication). Both are quarterly publications, and the sample size is, conservatively, 600 papers in each journal (http://www.sfaa.net/). Again, the numbers are not encouraging. In each journal, only eight articles discuss diversity in organizations in any context, and of these only two, both in Human Organization, address diversity management specifically: Natcher, Davis, and Hickey (2005) examine the degree to which cultural differences enhance or hinder the working-group effectiveness of resource co-management boards established under Canada's first nations land claims process, and Reeves-Ellington (1995) explores ethnicity in global organizations. This pattern appears likely to be typical worldwide: Anthropology in Action, the leading applied anthropology journal in the United Kingdom, published only two diversity-related papers (of over 60) since 2005 (http://journals.berghahnbooks.com/aia/).

Of course, a reasonable objection to these findings is that a great deal of applied anthropology work is documented only in organizational reports. For many possible reasons, including the often sensitive nature of issues associated with diversity management, these reports may not result in disciplinary presentations or publications. This might in particular be the case with cultural audits, as while it is here that anthropological ethnographic expertise would best lend itself to the managing diversity process, it is also where the most sensitive information would tend to be produced.

Therefore, in order to get an idea of what constitutes a typical cultural audit report, a Google search was conducted (on March 12 and 13, 2011) of the keywords "diversity audit [and] assessment" (which would also capture "diversity needs assessment," a common variant). The 
first 25 independent websites listed in the search results that provided diversity management organizational reports or report summaries containing descriptions of the full range of audit methods used were collected. Similarly, the first 25 independent diversity consultant web sites describing diversity audit methodology (and whose firms were not involved in the development of the reports on the first list) were collected as well. The rationale for two different lists was to obtain information on both specific instances of auditing work and descriptions for methods that might be used in multiple projects. Cultural audit "how to" sites, as well as advertisements and testimonials for specific auditing instruments, were not used. As it was an English language search, the resulting sample was of full and summarized reports of audits in primarily American, European Union, and Australian business and educational organizations, as well as both large and small consulting firms from the United States and Europe. This is far from an adequate statistical sample, of course, as there are no doubt thousands of diversity audit reports and inhouse or external diversity auditors worldwide. However, it is probably a relatively random one. Google lists its search results based on several criteria, including the number of links to a web page from other pages and the "quality" (reputability and/or longevity) of the linking sites (http://www.google.com/librariancenter/articles/0512_01.html). Because these criteria are unrelated to the questions being explored, they are unlikely to bias findings in any particular direction.

The search results suggest a relative lack of anthropological theory and methods in the typical diversity-related cultural audit. First, the academic backgrounds of preparers of the 25 audit reports and summaries were examined to identify how many assessors have formal anthropological training. Academic information was found either in the documents themselves or through Google author name searches (for example, many authors" educational information was listed on linkedin.com). Author backgrounds were found for 20 of the 25 reports, for a total of 56 academic profiles (some audits involved multiple authors, and several authors listed degrees in more than one field). While the disciplines listed were wide-ranging, including industrial/organizational, social, experimental, and developmental psychology, social work, sociology, business administration, management, law, education, and others, anthropology was not represented.

In no case were the terms "anthropological" or "ethnographic" used to describe audit methods. However, because anthropological method and theory might nevertheless inform audit protocols, the number and types of cultural audit methods in each of the 50 descriptions were examined. The typical cultural audit methods are document reviews, interviews, focus groups, and surveys (questionnaires). Most protocols (32) describe the use of two or more of these, and 27 describe the use of three or more. However, 13 audit methodologies consist only of surveys, four of only focus groups, and one of only document reviews. Of those using interviews (29), nine are described as involving only organization leaders as respondents. In two cases, "diversity champions," or members of the workforce identified by leaders or consultants as influential, are listed as interviewees as well. Focus groups (29), where described in more detail (nine), are typically composed of individuals selected by race and gender (seven), with two more cases of additional selection by functional area. Only three of the surveys (37) are described as customized - that is, developed as a consequence of findings through interviews or other methods. In one of these cases, customization is derived from leadership meetings. Of the rest, seven are stand-alone instruments developed by assessors or other vendors. And only one methodological description in the sample notes the use of systematic observation as part of the audit process, while two refer to the use of "anecdotal observations." 
As preliminary as they are, these observations nevertheless provoke some questions regarding the potential use of anthropological theory and methods in cultural audits. While applied anthropologists do typically use interviews, focus groups, and surveys in their work, "triangulating" data obtained by means of several different methods (Denzin, 2006; Jick 1979) is considered essential (Trotter \& Schensul, 1998). As Fetterman puts it, "Triangulation is basic in ethnographic research. It is at the heart of ethnographic validity..." (1998, p. 496). Results from various collection strategies are compared so that data generated by one method are crosschecked and further investigated using another. This is ideally an iterative process, with additional questions developed as a consequence of earlier findings (Whitehead, 2005). This triangulated, iterative approach is expected to reduce bias and increase the validity of conclusions. Thus, stand-alone surveys are usually rejected in favor of those developed from other data sources to more accurately capture questions relevant to particular cultural settings. A minimum of 40 percent of surveys described in the sample are necessarily stand-alone, and over a third of the protocols described involve the use of only one method, in both cases reflecting the lack of fundamental anthropological methodology.

In addition, participant-observation, a keystone of traditional ethnography, is increasingly accepted to often be unfeasible in applied anthropology projects due to the length of time it requires, and several protocols, such as rapid ethnographic assessment (Beebe, 2001) and quick ethnography (Handwerker, 2002) have been developed to overcome this problem (although not without criticism; e.g., Bate, 1997) . However, observation, ideally structured, remains seen as necessary (Beebe, 2008). Diversity audits, at least those involving multiple methods, are typically of sufficient length to permit the gathering of observational data. It is therefore also suggestive that only one of the audit protocols specifically describes systematic observation as a method.

Further, applied anthropologists are trained to question assumptions, especially around what LeCompte and Schensul (1999) call codes. Coding is simply rigorously identifying and organizing patterns of phenomena. Applied anthropologists strive to develop codes that are clearly defined, discrete in some supportable way, and related to "naturally" occurring aspects of behavior, in order to facilitate value-free analysis as much as possible. However, there are also often "pre-codes," including categorizations of groups of people, used by clients and/or participants in a given cultural setting in reference to issues, target populations, etc. These can not only incorrectly define problems and relationships but also be improperly legitimized if accepted a priori by researchers. An important contribution of the anthropological approach lies in testing assumptions in existing codes, as well as where necessary developing alternatives ones that better reflect the nature of problems, in both cases assuring code validity as meaningful to those being questioned or observed on their basis (LeCompte \& Schensul, 1999).

In diversity management, diversity dimensions involving race, ethnicity, gender, and others are often pre-codes, the applicability of which with respect to organizational issues is sometimes open to question. In a limited sense, Thomas attempted to address this problem by focusing on organizational effectiveness in addressing a given mix of diversity dimensions, present or future, identified or not. However, in many cases diversity management programs, sometimes even as they cite Thomas's work, explicitly describe diversity as related to race/ethnicity and gender (e.g., Knowledge@Wharton, 2006). One possible example of this pre-coding trend in the sample is the use of focus groups formed on the basis of race and gender, apparently under the assumption that these will be the most relevant dimensions to an audit. 
A related issue is the degree to which participants in audits are appropriately sampled. As one diversity management program description notes,

\begin{abstract}
"[Diversity audits] can...be conducted across an entire employee population, a sample of the employee population, in specific locations, or with employee groups, such as disabled employees. You should only focus on particular groups, however, when you are already conducting some form of diversity audit across the entire population. Failure to do so sends the message that the organisation is only interested in the views of some employees" (http://www.diversityworksfor london.com/server/show/nav.00600b003).
\end{abstract}

This is good advice, and the perception of preferential treatment is certainly a concern, but as important is that inadequately sampling on the basis of particular dimensions may limit the opportunity to obtain data relevant to organizational culture issues. As noted earlier, key to diversity management is the expectation that dimensions that most impact organizations will not necessarily stem from a list of likely candidates. More fundamentally, applied anthropology's focus on those who are most directly affected by problems and processes necessitates work with all levels of a workforce. Because culture is shaped from all directions, organizational subcultures may be operating in concert or conflict with each other, irrespective of management views and plans (Jordan, 1995; Reynolds, 1994). Thus, if cultural audits focus on leadership perceptions, as appears to be the case in at least nine of the protocols sampled, they do not reflect basic anthropological methodological assumptions.

In sum, whether or not anthropologists are directly involved, it seems likely that anthropological method and theory do not often contribute to diversity-related cultural audits. This might be unsurprising if the anthropological approach in some sense precluded such instruments, but a workable model consistent with the anthropological approach as discussed above is easy to envision and has been successfully used (e.g., Qirko, 2007). Such a model involves many of the same data collection methods found in other audits: client/leadership interviews; document reviews; semi-structured interviews; focus groups; systematic observation; and organization-wide surveys. However, here multiple methods are used iteratively, particularly so that survey instruments are developed in large part on the basis of data gleaned from other methods. Further, interviews involve both random and representative sample components, the latter by as many typical dimensions of difference as possible (age, gender, race/ethnicity, sexual orientation, disability, tenure, level, job function, geographic location, etc.). To accommodate such representation, the interview sample is large, perhaps as much as 10 to 15 percent of the workforce. Similarly, focus group composition is either random or involves a sufficient number of typical dimensions to avoid selection bias as much as possible, or both. Focus group, interview and survey questions ask respondents how well they think organizational systems and structures are working, both for themselves and others. And of course, systematic observation takes place in a variety of contexts, including individual workplaces, meetings, employee functions, and so forth. Thematic analyses, coupled with scaled survey data, provide a mixture of qualitative and quantitative data that are both measurable and rich in detail.

Similarly, analysis involves data obtained from all methods used, and focuses on the effectiveness of systems and practices in dealing with both identifiable and unforeseen workforce differences; organizationally-salient cultural and subcultural groups; and organizational cultural and subcultural beliefs and assumptions. This approach provides for a reasonably ground-up, 
iterative, and triangulated process, and assumes the broadest view of diversity. This is but one possible model, of course, but it suggests that there is no reason why rigorous anthropological audit methods can't be used in the diversity management process.

\section{BARRIERS TO ANTHROPOLOGICAL INVOLVEMENT}

Assuming, as argued, that anthropology is underrepresented in diversity management assessment work, several factors might be involved. It is possible that many anthropologists do indeed work in diversity management, but primarily as trainers and not assessors. Some researchers have discussed the value of anthropology to diversity training (e.g., Garcia, 1995; Hogan, 2007; Pollack, 1997). Further, anthropologically trained practitioners sometimes list diversity training as a competency, and several university anthropology programs describe diversity training as a productive area of employment for graduates. Certainly diversity training content is at least superficially consistent with much of what anthropologists routinely teach in introduction to cultural anthropology courses. However, many sources suggest that the effectiveness of diversity training is open to question in terms of both increasing representation of women and minorities (e.g., Dobbin, Kalev, \& Kelly, 2007; Kalev et al., 2006; Kidder et al., 2004; Nancherla, 2008) and in sensitizing workforces to diversity-related issues (e.g., Paluck, 2006). The latter appears to be the case particularly when training is not voluntary (Dobbin et al., 2007) or is perceived as closely tied to affirmative action initiatives (Whittenburg, Marcus, Tesolowski, \& Isbell, 2001). Therefore, many of the objections anthropologists are likely to have to diversity management assessment work, as listed below, will apply to both diversity training and cultural assessments.

Certainly anthropologists and others have been critical of several aspects of diversity management programs, suggesting the possibility of disengagement from the field, as has been documented regarding applied work in other problematic areas such as development (Escobar, 1995; Lewis, 2005). Of particular concern are essentialist assumptions considered by some inherent in diversity work, in that 'socio-demographic characteristics are considered constitutive of human beings" essences, leading to a view of identity as a given, fixed essence [that] reflects essential differences in attitude, personality and behaviour" (Janssens \& Zanoni, 2005, p. 313; see also Bendl, Fleischmann, \& Walenta, 2008; Litvin, 1997; Nkomo \& Cox, 1996; Wrench, 2005). A related movement is a critique of cultural representationalism (Brightman, 1995; Rapport \& Overing, 2000). In this view, the concept of cultures as mutually exclusive, stable, and consistent categories is better replaced with "culturing," or the agent-driven, active manipulation of (and resistance to) cultural forms. In effect, there are no cultures: "For most people around the world, culturing is an endless, and ever ongoing, overt activity, which ill fits the social scientist's categories," and so the reification of cultural categories is an illusory and dangerous undertaking (Rapport \& Overing, 2000). Thus, by the 1990s, even many anthropologists working in business 'seemed more interested in the blurring and crossing of boundaries than in descriptions of what they might demarcate" (Baba, 2006, p. 27).

Diversity management programs, from these perspectives, perpetuate and reinforce essentialist cultural categories, which in turn can perpetuate inequality. Further, this process leads to a backlash: "Instead of creating an atmosphere of tolerance and respect within the workplace, diversity management interventions would appear to have engendered responses of antagonism and resentment on the part of the "managed diverse"" (Lorbiecki \& Jack, 2000, p. 29). Even in a diversity model that includes multiple dimensions, essentialism remains an issue. 
The paradox, of course, is that in studying group processes, or even group effects, there is no way to avoid some measure of typologizing. The solution, at least as theoretically formulated by Thomas, is to design or modify organizational systems so that they work for any and all, and so specific dimensions of difference become irrelevant. However, in practice this is difficult to accomplish. For example, developing "blind" interview protocols might be a way to address diversity-related issues in hiring practices, but the cost is the potential loss of much appropriately relevant information to employers, and even the simplest "race-blind" college admission protocols have been shown to be difficult to effectively design (e.g., Vultaggio, 2008).

In turn, some argue that diversity management does not essentialize enough - that is, that the goal of diversity management should be to address racial/ethnic and gender power imbalances, and thus to explicitly define diversity along the lines of historical oppression and its enduring consequences (e.g., Cross, Katz, Miller, \& Seashore, 1994; Gordon, 1995; Wrench, 2005). Thus Konrad argues that "Rather than attempting to include all individual differences within the workplace diversity domain, the workplace diversity literature should focus on the study of identity groups in organizations" (2003, p. 7), as power relations among such groups cannot, and should not, be ignored.

Academic debate regarding this issue seems to be accompanied by confusion in organizations themselves. As discussed earlier, many companies practically focus on gender and racial/ethnic representation in spite of their broader rhetoric (e.g., Castro, 2010; Ryan et al., 2002), and one study found that almost three-quarters of a sample of 1400 human resource professionals reported that their organizations "did not have an official definition of diversity" (SHRM, 2008). Clearly variability in conceptualizations of diversity in organizations, as well as among anthropologists, will influence anthropological interest and participation in specific diversity management programs.

Another possible cause for anthropological disengagement relates to a longstanding debate about whether culture is an attribute an organization possesses, and so an independent variable that can be managed, or is instead a largely unmanageable social reality (Smircich, 1983). If the latter, culture "is not a separable facet of an organisation, it is not readily manipulated or changed, and it is not created or maintained primarily by leaders" (Willcoxson \& Millett, 2000, p. 93). In fact, as Reynolds has shown, culture is "a stubborn fact of social organization" (1994, p. 310) that can undermine managerial initiatives. Thus, diversity "management" may in fact be an illusion, and interpersonal relations may influence workforce culture more than managerial interventions (Krackhardt \& Kilduff 1990, p. 142). Here anthropologists in general differ substantially from colleagues in management and related fields who tend to view culture as heavily, if not predominantly, molded from the top (Knights \& Wilmott, 2007, pp. 344-374; Meek, 1988). As Meek put it, "Most anthropologists would find the idea that leaders create culture preposterous: leaders do not create culture, it emerges from the collective social interaction of groups and communities" (1988, p. 459). Many anthropologists may therefore be unwilling to participate in initiatives driven by what they perceive as a flawed and dangerous model of culture, particularly when, in practice, cultural audits often focus primarily on leadership perceptions of their organizational cultures.

However, this issue cannot be reduced simply to whether or not culture is manipulable, as applied anthropologists are routinely and uncontroversially involved in culture change initiatives. In fact, anthropologists are particularly suited to address conflicts which arise from the "stubbornness" of culture - or, put another way, from the tension between rational (planned, often managerial) and natural (social/psychological) organizational systems (Scott, 2002). As 
Baba argues (2005, p. 244), "The interaction of these different kinds of organizational systems is responsible for many issues and challenges in corporations, especially in cases where natural systems contradict managerial intent." Diversity issues are a telling case in point.

A third reason for potential disengagement is that many anthropologists could be reluctant to become involved with business at all, or as one graduate student put it, in 'selling yourself to the devil" (Sunderland \& Denny 2007, p. 31). Notwithstanding Laura Nader's well-known admonition to anthropologists to "study up," as "our lives themselves may depend upon the extent to which citizens understand those who shape attitudes and actually control institutional structures" (1972, p. 285), academic anthropology's view of business and industry is often quite critical (Baba, 2006). Further, in working for management, as is inevitable in diversity management programs, there are a number of practical and ethical issues for the anthropologist to navigate. Management will often, and unsurprisingly, attempt to "manage" anthropologists" access, methods, funding, and even findings and their dissemination (Baba, 2006). And a number of additional problems are created when cultural audits unearth problems involving the very same leaders who manage the auditors. Further, "there is always a risk that those in power will use findings against, rather than for, intended beneficiaries of anthropological work" (RylkoBauer, Singer, \& van Willigen, 2006, p. 183), including in employee retaliation and perhaps as "cover for a more sanctioned and selective form of racism" (Gordon, 1995, p. 17). Given this, it would not be surprising if many anthropologists resisted involvement: these issues can make business anthropology "difficult, frustrating, and risky, and could help to explain why there is not more of it after all these years. Some anthropologists have concluded that strategic research on organizational behavior is impossible because of the contradictions just described..." (Baba, 2006, p. 35; emphasis in original)

From the perspective of business, there are several additional reasons why anthropologists and their methods might not more commonly be used in diversity management programs. One relates to the motivations underlying business diversity initiatives. The fact that so many organizations now have diversity programs in place, by itself, says little. Businesses often institute policies because their competitors have done so, and sometimes it seems that the competitive edge diversity management provides lies in an organization's being able to claim that it is a leader in the area. This is particularly evident in diversity awareness training (Nancherla, 2008). To what extent this might be typical is an open question, but a 2004 survey of 5500 hundred American workers found that only 32 percent felt their companies had effective diversity programs. Further, fewer than half of respondents felt that leadership at their companies was committed to diversity or held itself and others accountable for progress in this area (National Urban League, 2005). Five years later, a follow-up survey of 1258 workers showed more favorable perceptions of the effectiveness of diversity initiatives in their companies, but still fewer than half responded positively, and favorables actually went down for leadership commitment and accountability (National Urban League, 2009). Similarly, in Europe an ECcommissioned survey of 335 businesses found that nearly half reported no equity and diversity policies in place, and a lack of leadership commitment was cited by 40 percent as the most important issue in dealing with diversity issues in practice in their organizations (Focus Consultancy, 2008). To the extent that these findings may reflect the use of diversity management as "colorful window dressing" (Marques, 2010; see also McVittie, McKinlay, \& Widdicombe, 2008; Wrench, 2005), rigorous and costly audits are unlikely to be perceived by businesses as necessary. 
A second factor may relate to ambivalence around the business case for diversity. In the United States, the workforce demographic predictions in the Workforce 2000 Hudson Institute report have generally been borne out, if more slowly than expected (Judy \& D"Amico, 1997), and in many nations labor pools and their diversity ramifications are becoming increasingly complex (Clark \& Drinkwater, 2007; HLG, 2007; Vertovek, 2007). Further, as business becomes increasingly global, "we can no longer say anything sensible about the prospects for American workers if we consider only the U.S. economy or the characteristics of the U.S. labor force" (Judy \& D"Amico, 1997, p. 3), and this too applies to more and more areas of the globe. Thus one prong of the business case, that the best talent will increasingly come in a "different package" than that for which many organizations have been traditionally designed, is hard to contest.

However, the claim that diversity, or the mix of dimensions, in and of itself provides a competitive advantage remains difficult to support. Many studies find that diversity negatively impacts group functioning (Williams \& O'Reilly, 1998), while others suggest that only a small amount of diversity (10-30 percent) is optimal for work group effectiveness (e.g., Knouse \& Dansby, 1999). Ely and Thomas suggest that the effectiveness of diverse work groups increases only when organizations directly link diversity to work processes (2001; also Thomas \& Ely, 1996). And Kochan et al. (2003) argue that none of the business case arguments for diversity management are supported by evidence (see also Jayne \& Dipboye, 2004). Diversity-related workforce training and manager performance evaluations, two of the most common diversity management initiatives, do not appear to increase diversity in organizations, at least by race and gender (Dobbin et al., 2007). Further, data related to the performance of homogeneous versus heterogeneous teams in a variety of contexts are at best mixed (e.g., Thomas, 1999; Watson, Kumar, \& Michaelsen, 1993). In fact, Kochan et al. suggest that diversity management advocates should abandon the business case altogether, and argue for diversity management programs on other grounds: "[W]hile there is no reason to believe diversity will naturally translate into better or worse results, diversity is both a labor market imperative and societal expectation and value" (2003, p. 31). One implication of an unsupported business case for diversity, however, is that here too, cultural audits may not be seen by business diversity managers as necessary investments.

Other reasons managers may be resistant to anthropologically-oriented audits pertain to the methods themselves. Some in business misconceive the anthropological approach, especially if they are familiar only with its historical applications, as too time consuming and costly compared with alternatives (Davenport, 1996; Jordan \& Dalal, 2006). More justifiably, it may be perceived as too qualitative, interpretive, or idiosyncratic. Jordan and Dalal find that a lack of generalizability in ethnographic methods is "one of the most deep-reaching objections we encounter [and] comes from managers" legitimate concerns about enterprise-wide solutions" (2006, p. 369). Indeed, sometimes associated with anthropology's particularistic emphasis is a tendency to view ethnography as a tool-kit from which the researcher draws as needed to explore cultural settings so unique that both methods and data belie replicability. This is not particularly congruent with managers" desire to conduct multiple assessments to assess the effectiveness of diversity interventions or to compare units within or among organizations (Qirko, 2007). However, while the importance of qualitative approaches in anthropology cannot be overemphasized (Jordan, 2010), ethnography is not by definition solely qualitative, and much ethnographic data is easily, and often, quantified. Hybrid methods, while sometimes criticized by 
both sides of the qualitative/quantitative debate (Martin, 2002), appear to be the best solution to this problem.

One final potential issue relates to marketing. While anthropologists are making strides in terms of their impact on public policy (Fiske, 2011), they appear to generally be poor selfpromoters, especially in the area of business, perhaps in part because they are aware that their approach will not always be of obvious value to businesses seeking "quick-fix" solutions (Moeran, 2003, p. 87). Meanwhile, while culture is a notoriously fuzzy concept, even in anthropology, it is at the same time perceived popularly as familiar and even mundane:

"Everyone is an expert on culture, or so they think...people, society and culture are familiar; we are enveloped in society in our everyday existence. This proximity leads people to believe they understand how society works, how it came to be the way it is, and how its institutions function" (Podolefsky, 2008, p. 79; see also Naylor, 1996, p. 16).

Business leaders, along with the general public, will often underestimate the value of a discipline that sometimes seems to take the obvious and render it incomprehensibly complex. Further, management and organizational scholarship has tended to minimize anthropological contributions to the subject of organizational culture (Moeran, 2003, p. 90). The concept of culture was rather "crudely" appropriated by management literature in the 1980s (Linstead 1997, p. 86), and anthropology has been unable or unwilling to take it back. Thus, for fuller involvement, the case for the value of anthropological approaches to diversity management must clearly be made by anthropologists themselves.

\section{CONCLUSION}

In sum, there appears to be a lack of anthropological involvement in business diversity management, and there are several potential reasons, from both anthropological and organizational perspectives, why this might be so. However, the gulf between anthropological and business conceptions of diversity management need not be insurmountable. Many of the issues described above can be addressed through effective marketing, clear contracting and, given the apparent confusion in organizations about what diversity management is or should be, even some direction on the part of anthropologists offering their services.

There are several good reasons why applied anthropology should be more involved in diversity management than it seems to be. First, as alluded to earlier, business-related diversity issues are clearly here to stay. The Hudson Institute's 2020 report predicts an increasingly diverse American workforce (Judy \& D”Amico, 1997). Similarly, Vertovek (2007) uses the term "super-diversity" to describe the increasing number and variety of demographic and cultural factors characterizing migrant movements and settlement patterning in the United Kingdom, but which apply elsewhere in Europe and around the world. Further, large numbers of people around the world are becoming more affluent as their nations experience dramatic growth, rendering markets, as well as multinationals corporations that serve them, increasingly numerous and diverse (Zakaria, 2011). Nevertheless, top levels of business and politics, even in the United States, the United Kingdom, and other "advanced" nations, still significantly under-reflect their populations in terms of race, ethnicity, gender, and other diversity dimensions (e.g., Bohnet \& Lund, 2009; Daniels, 2004; European Commission, 2007; ILO, 2007). 
Second, the goals, theory and methods of anthropology remain particularly well suited for diversity work. Hannerz has argued that diversity is anthropology's best disciplinary "brand": "A consistent emphasis on "diversity" as what anthropology is about best matches our combined interests and practices" (2010, p. 539). Further, specifically regarding organizational diversity, "we should take the public demand for knowledge and insight in [diversity management] seriously and consider further how we can meet that demand in our way" (p.545).

But perhaps the most important reason for anthropological involvement in diversity management remains Nader's admonition to 'study up." Gordon has written that "Those of us in academic cultural studies have not been paying enough attention to the fact that there is a whole parallel intellectual sphere [in corporations] where writing and thinking about culture, diversity, multiculturalism, and so on occurs" (Gordon, 1995, p. 4). His argument is ultimately that "corporate culture diversity management is a monitory and influential example of liberal racism" (p.4), and while some may disagree with his conclusion, key in his statement is the word "influential." Corporate culture's values and assumptions spill beyond organizational walls into the non-corporate world, influencing not only economic, but political and social thinking as well. As Moeran puts it,

"[T]he joint-stock company is probably one of the most prevalent social institutions to be found anywhere in the world today. What such business organizations do, how they distribute wealth, where they choose to locate their premises, how many and what kind of people they employ, what kind of research they carry out, what sporting or cultural events they choose to sponsor, and so on and so forth, have enormous financial, economic, administrative, governmental, environmental, social and cultural consequences" (2003, p. 90; emphasis in original).

Business is a major force shaping culture, and so the more fully it is studied, and first-hand, the better a host of societal dynamics can be understood. Effective diversity management ultimately leads, by definition, to increasingly diverse perspectives at the highest levels of business and other organizations. This in turn inevitably means that more diverse perspectives will influence goals and strategy around the kinds of decisions to which Moeran refers, with potentially positive consequences for local, national, and global communities. It is hard to see why anthropologists, especially the many who view advocacy of equity and inclusion as inseparable from anthropological pursuits, wouldn't want to be involved in that process.

\section{REFERENCES}

Ashkanasy, N. M., Härtel, C. E. J., \& Daus, C. S. (2002). Diversity and emotion: The new frontiers in organizational behavior research. Journal of Management, 28, 307-338.

Baba, M. (2000). Theories of practice in anthropology: A critical appraisal. National Association for the Practice of Anthropology Bulletin, 18, 17-44.

Baba, M. (2005). Anthropological practice in business and industry. In S. Kedia \& J. van Willigen (Eds.), Applied anthropology: Domains of application (pp. 221-262). New York, NY: Praeger. 
Baba, M. (2006). Anthropology and business. In H. J. Birx (Ed.), Encyclopedia of Anthropology (pp. 83-117). Thousand Oaks, CA: Sage. Retrieved from

https://www.msu.edu/ mbaba/publications/Encyclopedia\%20of\%20Anthropology\%20Final.pdf (NOTE: paginated 1-51).

Baba, M. L., \& and Hill, C. E. (2006). What's in the name "applied anthropology"? An encounter with global practice. In C. E. Hill \& M. L. Baba (Eds.), The globalization of anthropology (pp. 176-207). NAPA Bulletin \#25. Washington, DC: American Anthropological Association.

Bate, S. P. (1997). Whatever happened to organizational anthropology? A review of the field of organizational ethnography and anthropological studies. Human Relations, 50, 1147-1175.

Beebe, J. (2001). Rapid assessment process: An introduction. Walnut Creek, CA: AltaMira.

Beebe, J. (2008). Rapid assessment process. In L. M. Given (Ed.), The sage encyclopedia of qualitative research methods (Vol. 1). Thousand Oaks, CA: Sage. Retrieved from http://www.sage-ereference.com/abstract/research/n365.xml

Bendl, R., Fleischmann, A., \& Walenta, C. (2008). Diversity management discourse meets queer theory. Gender in Management, 23, 382-394.

Bennett, D. (2010, April 9): Who's still biased? Boston Globe. Retrieved from http://www.boston.com/bostonglobe/ideas/articles/2010/03/07/whos_still_biased/

Bohnet, I., \& Lund, T. (Eds). 2009. Closing the gender gap. Insights. Cambridge, MA: Harvard Kennedy School Women and Public Policy Program. Retrieved from http://www.hks.harvard.edu/var/ezp_site/storage/fckeditor/file/pdfs/centersprograms/centers/wappp/insights/insights_sp09.pdf

Brightman, R. (1995). Forget culture: Replacement, transcendence, relexification. Cultural Anthropology, 10, 509-546.

Castro, M. (2010, June 21). The business case for diversity: As public companies cut diversity programs, minorities and companies alike may suffer. Washington Business Journal. Retrieved from http://www.bizjournals.com/washington/stories/2010/06/21/focus $1 . h t m l$ ?page=all

Caulkins, D., \& Hyatt, S. B. (1999). Using consensus analysis to measure cultural diversity in organizations and social movements. Field Methods, 11, 5-26.

Chambers, E. (1985). Applied anthropology: A practical guide. Englewood Cliffs, NJ: PrenticeHall. 
Clark, K., \& Drinkwater, S. (2007). Ethnic minorities in the labour market: Dynamics and diversity. Bristol, England: Policy Press. Retrieved from http://www.jrf.org.uk/sites/files/jrf/1986-ethnic-minorities-employment.pdf

Cox, T. (1993). Cultural diversity in organizations: Theory, research and practice. San Francisco, CA: Berrett-Koehler.

Cox, T., \& Blake, S. (1991). Managing cultural diversity: implications for organizational competitiveness. Academy of Management Executive, 5, 45-56.

Cross, E. Y., Katz, J. H., Miller, F. A., \& Seashore, E. W. (Eds.). (1994). The promise of diversity: Over 40 voices discuss strategies for eliminating discrimination in organizations. New York, NY: Irwin.

Daniels, C. (2004, June 28). 50 best companies for minorities. CNN Money. Retrieved from http://money.cnn.com/magazines/fortune/fortune_archive/2004/06/28/374393/index.htm

Davenport, T. H. (1996). Joining the culture club. CIO, 10, 48-50.

Denzin, N. (Ed.). (2006). Sociological methods: A sourcebook. Piscataway, NJ: Aldine Transaction.

Dobbin, F., Kalev, A., \& Kelly, E. (2007). Diversity management in corporate America. Contexts, 6, 21-27.

Ely, R. J., \& Thomas, D. A. (2001). Cultural diversity at work: The effects of diversity perspectives on work group processes and outcomes. Administrative Science Quarterly, 46, 229273.

Escobar, A. (1995). Encountering development: The making and unmaking of the Third World. Princeton, NJ: Princeton University Press.

Essed, P. (2002). Cloning cultural homogeneity while talking diversity: Old wine in new bottles in Dutch organizations. Transforming Anthropology, 11, 2-12.

European Commission (2007). Discrimination in the European Union. Special Eurobarometer 263. Retrieved from http://ec.europa.eu/public_opinion/archives/ebs/ebs_263_en.pdf

Fetterman, D. M. (1998). Ethnography. In L. Bickman \& D. J. Rog (Eds.) Handbook of applied social science research methods (pp. 473-504). Thousand Oaks, CA: Sage.

Fine, M. G. (1996). Cultural diversity in the workplace: The state of the field. Journal of Business Communication, 33, 485-502.

Fiske, S. J. (2011). Anthropology's voice in the public policy process. Anthropology News, 52, 17. 
Focus Consultancy (2008). Diversity management in 2008: Research with the European business test panel. Brussels, Belgium: European Commission. Retrieved from ec.europa.eu/social/BlobServlet?docId=771\&langId=en

Garcia, M. H. (1995). An anthropological approach to multicultural diversity training. Journal of Applied Behavioral Science, 31, 490-504.

Gardenswartz, L., \& Rowe, A. (2010). Managing diversity: A complete desk reference \& planning guide. Alexandria, VA: Society for Human Resource Management.

Giovanni, M. J., \& Rosansky, L. M. H. (1990). Anthropology and management consulting. National Association for the Practice of Anthropology Bulletin, 9, 1-48.

Gordon, A. (1995). The work of corporate culture: Diversity management. Social Text, 44, 3-30.

Gwynne, M. A. (2003). Applied anthropology: A career-oriented approach. Boston, MA: Allyn \& Bacon.

Handwerker, W. P. (2002). Quick ethnography: A guide to rapid multi-method research. Walnut Creek, CA: AltaMira.

Hannerz, U. (2010). Diversity is our business. American Anthropologist, 112, 539-551.

HLG (High Level Advisory Group of Experts on the Social Integration of Ethnic Minorities and their Full Participation in the Labour Market) (2007). Ethnic minorities in the labour market: An urgent call for better social inclusion. Brussels, Belgium: European Commission. Retrieved from http://ec.europa.eu/employment_social/fundamental_rights/pdf/hlg/etmin_en.pdf

Hogan, M. (2007). Four skills of cultural diversity competence: A process for understanding and practice. Belmont, CA: Brooks/Cole.

ILO (2007) Equality at work: Tackling the challenges. Geneva, Switzerland: International Labour Office. Retrieved from

http://www.ilo.org/public/portugue/region/eurpro/lisbon/pdf/equality_07.pdf

Jayne, M. E. A., \& Dipboye, R. L. (2004). Leveraging diversity to improve business performance: Research findings and recommendations for organizations. Human Resource Management, 43, 409-424.

Jamieson, D., \& O'Mara, J. (1991). Managing workforce 2000: Gaining the diversity advantage. San Francisco, CA: Jossey-Bass.

Janssens, M., \& Zanoni, P. (2005). Many diversities for many services: Theorizing diversity (management) in service companies. Human Relations, 58, 311-340. 
Jick, T. A. (1979). Mixing qualitative and quantitative methods: Triangulation in action. Administrative Science Quarterly, 24, 602-611.

Johnston, W. B., \& Packer, A. E. (1987). Workforce 2000: Work and workers for the 21st century. Indianapolis, IN: Hudson Institute.

Jordan, A. T. (1995). Managing diversity: Translating anthropological insight for organizational studies. Journal of Applied Behavioural Science, 31, 124-140.

Jordan, A. T. (2010). The importance of business anthropology: Its unique contribution. International Journal of Business Anthropology, 1, 7-17.

Jordan, B., \& Dalal, B. (2006). Persuasive encounters: Ethnography in the corporation. Field Methods, 18, 359-381.

Judy, R. W., \& D"Amico, C. (1997). Workforce 2020: work and workers in the 21st century. Indianapolis, IN: Hudson Institute.

Kalev, A., Kelly, E., \& Dobbin, F. (2006). Best practices or best guesses? Assessing the efficacy of corporate affirmative action and diversity policies. American Sociological Review, 71, 589617.

Kidder, D., Lankau, M. J., Chrobot-Mason, D., Mollica, K. A., \& Friedman, R. A. (2004). Backlash toward diversity initiatives: Examining the impact of diversity program justification, personal and group outcomes. International Journal of Conflict Management, 15, 77-102.

Knights, D., \& Wilmott, H. (2007). Introducing organizational behaviour and management. London, England: Thomson Learning.

Knouse, S. B., \& Dansby, M. R. (1999). Percentage of work-group diversity and work-group effectiveness. Journal of Psychology, 133, 486-494.

Knowledge@Wharton (2006, March 16). Diversity in corporate America: Still a work in progress. Retrieved from http://knowledge. wharton.upenn.edu/article.cfm?articleid=1406

Kochan, T., Bezrukova, K., Ely, R., Jackson, S., Joshi , A., Jehn, K., ... Thomas, D. (2003). The effects of diversity on business performance: Report of the diversity research network. Human Resource Management, 42, 3-21.

Kogod, S. K. (1994). The Bridges Process: Enhancing organizational cultures to support diversity. National Association for the Practice of Anthropology Bulletin, 14, 27-47.

Konrad, A. M. (2003). Defining the domain of workplace diversity scholarship. Group and Organization Management, 28, 4-17. 
Krackhardt, D., \& Kilduff, M. (1990). Friendship patterns and culture: The control of organizational diversity. American Anthropologist, 92, 142-154.

Lattimer, R. L. (1998). The case for diversity in global business, and the impact of diversity on team performance. Competitiveness Review, 8, 3-17.

LeCompte, M. D., \& Schensul, J. J. (1999). Analyzing \& interpreting ethnographic data. Walnut Creek, CA: AltaMira.

Lewis, D. (2005). Anthropology and development: The uneasy relationship. In: J. G. Carrier (Ed.), A handbook of economic anthropology (pp. 472-486). Cheltenham, England: Edward Elgar.

Linstead, S. (1997). The social anthropology of management. British Journal of Management, 8, 85-98.

Litvin, D. (1997). The discourse of diversity: From biology to management. Organization, 4, 187-209.

Lorbiecki, A., \& Jack, G. (2000). Critical turns in the evolution of diversity management. British Journal of Management, 11, S17-S31.

Loden, M. (1996). Implementing diversity. Chicago, IL: Irwin.

Loden, M., \& Rosener, J. B. (1991). Workforce America! Managing employee diversity as a vital resource. Homewood, IL: Business One Irwin.

Marcus, G.E., \& Fischer, M. M. J. (1986). Anthropology as cultural critique: An experimental moment in the human sciences. Chicago, IL: University of Chicago.

Marques, J. F. (2010). Colorful window dressing: A critical review on workplace diversity in three major American corporations. Human Resource Development Quarterly, 21, 435-446.

Martin, J. (2002). Organizational culture: Mapping the terrain. Thousand Oaks, CA: Sage.

McVittie, C., McKinlay, A., \& Widdicombe, S. (2008). Organizational knowledge and discourse in employment. Journal of Organizational Change Management, 21, 348-366.

Meek, V. L. (1988). Organization culture: origins and weaknesses. Organization Studies, 9, 453473.

Moeran, B. (2003). The business of anthropology: Communication, culture and Japan.

Copenhagen Journal of Asian Studies, 17, 87-109.

Mor Barak, M. (2005). Managing diversity: Toward a globally inclusive workplace. Thousand Oaks, CA: Sage. 
Nader, L. (1972). Up the anthropologist: Perspectives gained from studying up. In D. Hymes (Ed.), Reinventing anthropology (pp. 285-311). New York, NY: Pantheon.

Nancherla, A. (2008). Why diversity training doesn't work... right now. Training and Development, 62, 52-58.

Natcher, D. C., Davis, S., \& Hickey, C. G. (2005). Co-management: Managing relationships, not resources. Human Organization, 64, 240-250.

National Urban League (2005). Diversity practices that work. Retrieved from http://www.nul.org/sites/default/files/Diversity_Practices_That_Work_2005.pdf

National Urban League (2009). Diversity practices that work II. Retrieved from http://www.nul.org/sites/default/files/Diversity_Practices_That_work_2009.pdf

Naylor, L. L. (1996). Culture and change: An introduction. Westport, CT: Bergin and Garvey.

Nkomo, S. \& Cox, T. (1996) Diverse identities in organizations. In S.R. Clegg, C. Hardy \& W.R. Nord (Eds.), Handbook of organization studies (pp. 338-356). London, England: Sage.

Nolan, R. W. (2008). Using anthropology overseas. National Association for the Practice of Anthropology Bulletin, 29, 166-180.

Paluck, E. L. (2006). Diversity training and intergroup contact: A call to action research. Journal of Social Issues, 62, 577-595.

Pelto, P.J., \& Pelto, G. H. (1978). Anthropological research: The structure of inquiry. Cambridge, England: Cambridge University Press.

Podolefsky, A. (2008). Applying anthropological knowledge. In P. C.Salzman \& P. C. Rice (Eds.), Thinking anthropologically: A practical guide for students (pp. 77-84). New York, NY: Pearson Prentice Hall.

Pollack, J. (1997). Anthropology and diversity training in teacher preparation. Anthropology News, 38, 7-10.

Qirko, H. N. (2007). Diversity and cultural assessments in business organizations. International Journal of Diversity in Organisations, Communities and Nations, 7, 151-158.

Rapport, N., \& Overing, J. (2000). Social and cultural anthropology: The key concepts (pp. 92102). London, England: Routledge.

Reeves-Ellington, R. (1995). Organizing for global effectiveness: Ethnicity and organizations. Human Organization, 53, 249-63. 
Reynolds, P.C. (1994). Culture on the tocks. In T. Hamada \& W.E. Sibley (Eds.),

Anthropological perspectives on organizational culture (pp. 301-310). Lanham, MD: University Presses of America.

Ryan, J., Hawdon, J., \& Brannick, A. (2002). The political economy of diversity: Diversity programs in Fortune 500 companies. Sociology Research Online, 7(1). Retrieved from http://www.socresonline.org.uk/7/1/ryan.html

Rylko-Bauer, B., Singer, M., \& van Willigen, J. (2006). Reclaiming applied anthropology: Its past, present, and future. American Anthropologist, 108, 178-190.

Schein, E. (1992). Organizational culture and leadership. San Francisco, CA: Jossey-Bass.

Schwartz, D. S. (2000). The case of the vanishing protected class: Reflections on reverse discrimination, affirmative action and racial balancing. Wisconsin Law Review, 2, 657-689. Retrieved from http://ssrn.com/abstract $=1499942$

Schwartzman, H. B. (1993). Ethnography in organizations. Newbury Park CA: Sage.

Scott, W. R. (2002). Organizations: rational, natural, and open systems. Englewood Cliffs, NJ: Prentice Hall.

Smircich, L. (1983). Concepts of culture and organisational analysis. Administrative Science Quarterly, 28, 339-358.

SHRM (2008). 2007 State of workplace diversity management. Alexandria, VA: SHRM Research Department. Retrieved from http://www.shrm.org/Research/SurveyFindings/Articles/Documents/The\%20State\%20of $\% 20$ Diversity\%20Managment $\% 20$ surevey\%20report.pdf

Sunderland, P., \& Denny, R. M. (2007). Doing anthropology in consumer research. Walnut Creek, CA: Left Coast.

Thomas, D. A., \& Ely, R. J. (1996). Making differences matter: A new paradigm for managing diversity. Harvard Business Review, 74, 79-90.

Thomas, D. C. (1999). Cultural diversity and work group effectiveness: An experimental study. Journal of Cross-Cultural Psychology, 30, 242-263.

Thomas, R. R., (1990). From affirmative action to affirming diversity. Harvard Business Review, 68, 107-117.

Thomas, R. R. (1991). Beyond race and gender: Unleashing the power of your total workforce by managing diversity. New York, NY: AMACOM. 
Thomas, R. R. (1992) Managing diversity: A conceptual framework. In S. E. Jackson (Ed.), Diversity in the workplace: Human resources initiatives (pp. 306-318). New York, NY: Guilford.

Thomas, R. R. (2010a). Curing diversity ills. Diversity Executive, May-June, 50. Retrieved from http://www.humancapitalmedia.com/eshop/categories/Newsstand/Back-Issues/DiversityExecutive-magazine-Back-Issues/

Thomas, R. R. (2010b). The ism is not the issue. Diversity Executive, November-December, 50. Retrieved from http://www.humancapitalmedia.com/eshop/categories/Newsstand/BackIssues/Diversity-Executive-magazine-Back-Issues/

Thomas, R. R. (2011). The business case revisited. Diversity Executive, May-June, 50. Retrieved from http://www.humancapitalmedia.com/eshop/categories/Newsstand/Back-Issues/DiversityExecutive-magazine-Back-Issues/

Thomas, R. R., with M. I. Woodruff (1999). Building a house for diversity: A fable about a giraffe \& an elephant offers new strategies for today's workforce. New York, NY: AMACOM.

Trotter, R. T., \& Schensul, J. J. (1998). Methods in applied anthropology. In H. R. Barnard (Ed.), Handbook of methods in cultural anthropology (pp. 691-736). Walnut Creek, CA: AltaMira.

van Willigen, J. (2002). Applied anthropology: An introduction. Westport CT: Bergin \& Garvey.

Vertovek, S. (2007). Super-diversity and its implications. Ethnic and Racial Studies, 29, 10241054.

Vultaggio, J. (2008, November 18). The illusion of race-blind admissions. Inside Higher Ed. Retrieved from http://www.insidehighered.com/views/2008/11/18/vultaggio

Walck, C., \& Jordan, A. T. (Guest eds.) (1995). Managing diversity: Anthropology's contribution to theory and practice. Journal of Applied Behavioral Science, 31, (2).

Watson, W.E., Kumar, K., \& Michaelsen, L. K. (1993). Cultural diversity's impact on interaction process and performance: Comparing homogeneous and diverse task groups. Academy of Management Journal 36, 590-602.

Whitehead, T. L. (2005). Basic classical ethnographic research methods: Secondary data analysis, fieldwork, observation/participant observation, and informal and semi-structured interviewing. Ethnographically Informed Community and Cultural Assessment Research Systems (EICCARS) Working Paper Series. Cultural Ecology of Health and Change (CEHC). Retrieved from http://www.cusag.umd.edu/documents/WorkingPapers/ClassicalEthnoMethods.pdf

Whittenburg, C. E., Marcus, M. H., Tesolowski, D. G., \& Isbell, C. H. (2001). The relationship of selected variables on diversity programs in Fortune 250 manufacturing firms. Journal of Industrial Teacher Education, 38(2). Retrieved from http://scholar.lib.vt.edu/ejournals/JITE/v38n2/whittenburg.html 
Wilcher, S. (2010). Affirmative actions vs. diversity. Insight into Diversity, Winter. Retrieved from http://www.insightintodiversity.com/editorial-board/274-shirley-j-wilcher.html

Willcoxson, L., \& Millett, B. (2000). The management organisational culture. Australian Journal of Management \& Organisational Behaviour, 3, 91-99.

Williams, K. Y., \& O’Reilly, C. A. (1998). Demography and diversity in organizations: A review of 40 years of research. In B. M. Straw \& L. L. Cummings (Eds.), Research in organizational behavior (pp. 77-140). Greenwich, CT: AI.

Wrench, J. (2005). Diversity management can be bad for you. Race \& Class, 46, 73-84.

Zakaria, F. (2011). The post-American world: Release 2.0. New York, NY: W. W. Norton.

\section{NOTE}

I am grateful to Bruce N. Tomaso and two anonymous reviewers for their contributions to earlier versions of this paper. 